\title{
Revision of Tipula (Yamatotipula) stackelbergi Alexander (Diptera, Tipulidae), and a short discussion on subspecies among crane flies
}

\author{
Jukka Salmela' \\ I Zoological Museum, Department of Biology, FI-20014 University of Turku, Finland \\ Corresponding author: Jukka Salmela (jueesal@utu.fi)
}

Academic editor: V. Blagoderov | Received 7 October 2011 | Accepted 1 December 2011 | Published 5 January 2012

Citation: Salmela J (2012) Revision of Tipula (Yamatotipula) stackelbergi Alexander (Diptera, Tipulidae), and a short discussion on subspecies among crane flies. ZooKeys 162: 43-58. doi: 10.3897/zookeys.162.2216

\begin{abstract}
All available type material of Tipula stackelbergi Alexander, T. usuriensis Alexander and T. subpruinosa Mannheims were examined. Tipula (Yamatotipula) stackelbergi stat. rev. is elevated from a subspecies of T. (Y.) pruinosa Wiedemann to a valid species. Two new synonyms are proposed: Tipula usuriensis syn. n. proved to be a junior synonym of. $T .(Y$.$) pruinosa and T$. subpruinosa syn. n. a junior synonym of $T .(Y$. freyana Lackschewitz. Tipula $(Y$.$) stackelbergi is redescribed, male and female terminalia of T$. (Y.) pruinosa are illustrated and discussed. Female terminalia of $T$. (Y.) freyana are described and illustrated for the first time. A key to both sexes of $T$. (Y.) stackelbergi and $T$. (Y.) pruinosa, and a key to females of $T$. (Y.) chonsaniana, $T .(Y$.$) freyana and T$. (Y.) moesta are provided. Subspecies are not uncommon among crane flies, but their ranges and traits are poorly known. An interdisciplinary approach (genetics, ecology, taxonomy) is suggested if subspecific ranks are to be used in tipuloid systematics.
\end{abstract}

\section{Keywords}

Palaearctic region, crane flies, Tipula, new synonyms

\section{Introduction}

The description of Tipula stackelbergi (Diptera, Tipulidae) was based on male holotype collected from Russian East Siberia (Alexander 1934). Later this species was also recorded from the Russian Far East (Savchenko 1961; Pilipenko 2009). Savchenko (1961) considered T. stackelbergi as a subspecies of T. pruinosa Wiedemann, based

Copyright Jukka Salmela. This is an open access article distributed under the terms of the Creative Commons Attribution License 3.0 (CC-BY), which permits unrestricted use, distribution, and reproduction in any medium, provided the original author and source are credited. 
on the small structural differences between the two taxa. He also transferred T. stackelbergi to the subgenus Tipula (Yamatotipula) Matsumura. In the same publication, Savchenko suggested two synonyms for T. stackelbergi, namely T. usuriensis Alexander, 1925 and T. subpruinosa Mannheims, 1954. However, both synonyms were uncertain because Savchenko did not examine the type material of these two species. The description of T. usuriensis was based on male holotype, collected from Siberia (exact locality uncertain) and the description of T. subpruinosa was based on two females, collected from northern Finland (holotype) and Sweden (paratype) (Alexander 1925; Mannheims 1954). Since the taxonomic treatment by Savchenko (1961), both species have remained synonyms of T. stackelbergi (e.g. Oosterbroek and Theowald 1992) and apparently the type material has remained unstudied. In addition, Tipula stackelbergi has been used as an example of a tipulid (sub)species with a large but disjunct range in the Palaearctic region (Oosterbroek et al. 2001).

Subspecies are traditionally held as geographically separate and genetically distinct populations within the species' range, permitting gene flow in the area of contact (Wilson and Brown 1953; O’Brien and Mayr 1991; Patten and Unitt 2002). Despite possible interbreeding between subspecies, subspecies may retain differences in respective life cycles or other traits (Hewitt 2002; Kothera et al. 2009). Among birds, high subspecies richness was associated with large breeding ranges, island dwelling, inhabiting montane regions, habitat heterogeneity and low latitude; on the other hand, species phylogenetic age was a poor predictor of subspecies richness (Phillimore et al. 2007). Definition of subspecies, and propensity of naming subspecific taxa, vastly differs among taxonomic groups. High proportions of higher plants, mammals and birds have subspecies, less so compared to invertebrates (Haig et al. 2006). New molecular methods have revolutionized subspecific classifications: i) formerly held subspecies gain no support at all, ii) subspecies are proposed to be valid species or iii) their status as operational evolutionary units is supported (Ball and Avise 1992; Patten and Unitt 2002; Tsao and Yeh 2008; Miller et al. 2011). Despite problems in correct recognition and delineation of subspecies, subspecific taxa are seen as powerful tools in conservation and as meaningful biological entities (Haig et al. 2006; Phillimore and Owens 2006).

In crane flies (Diptera, Tipuloidea) subspecific ranks are not uncommon. For example, out of 493 and 168 Palaearctic Tipulidae taxa described by C.P. Alexander (1889-1981) and E.N. Savchenko (1909-1994), respectively, 24 and 26 taxa are currently ranked as subspecies (data from Oosterbroek 2011). However, the recent tendency has been to elevate former subspecies to valid species (Starý 2006; Salmela and Autio 2009; Starý and Brodo 2009). In these cases, former subspecies are clearly separated upon differences in male and female hypopygial structures. In addition, due to the improved faunistic knowledge, range-sizes of former subspecies are in reality much larger than was previously known. On the other hand, some western Palaearctic (sub) species are most probably recent origin of Pleistocene glacial and interglacial periods; examples of such species are present in especially in the Iberian peninsula and Asia minor (Oosterbroek 1980). In general, tipuloid subspecies are elusive and very poorly known, and no rigorous assessment on the suitability of subspecific rank among crane 
flies has been carried out. Based on subjective opinion, perhaps a majority of the current Palaearctic tipuloid subspecies are in fact valid species. Furthermore, most allopatric or parapatric crane fly populations, that are genetically distinct from nominotypical (sub)species, are still to be found by biologists. Based on above mentioned references, subspecies should not be proposed on exiguous basis, relying on a small number of studied specimens and subtle differences in coloration or other structures. Instead, an interdisciplinary approach (genetics, ecology, taxonomy) is suggested if subspecific ranks are to be on a solid ground.

In this article I present the results of an examination of all available type material of T. stackelbergi, T. usuriensis and T. subpruinosa. I propose changes to the nomenclature of these species and I also review the morphology of T. pruinosa and T. stackelbergi, with an emphasis on male and female genitalia. In addition, female genitalia of $T$. (Y.) freyana are illustrated and a key to $T$. ( $Y$.) freyana and females of $T$. (Y.) chonsaniana and T. (Y.) moesta are provided.

\section{Material and methods}

The morphological terminology used here mainly follows Alexander and Byers (1981). Terminology of some special parts of male genitalia was taken from Frommer (1963) or is explained in the figures. The following acronyms for museums and collections are used in the text: MZHF - Finnish Museum of Natural History (Zoological Museum), University of Helsinki, Helsinki, Finland; PVM - Private Collection of V.-M. Mukkala, Kaarina, Finland; USNM - Smithsonian Institution, National Museum of Natural History, Washington DC, USA; ZMUC - Zoological Museum, University of Copenhagen, Copenhagen, Denmark; ZMUT - Zoological Museum, University of Turku, Turku, Finland; ZISP - Zoological Institute Russian Academy of Sciences, St. Petersburg, Russia. Due to the courtesy of Valentin Pilipenko (Moscow State University, Russia), I was able study high quality digital photos of male hypopygium of $T$. $(Y$.) pruinosa (Russia: Moscow, 1 male, Altay, 1 male) and $T$. (Y.) stackelbergi (Russia: Primorski kray, 1 male).

Layer photos were taken using an Olympus SZX16 stereomicroscope attached to an Olympus E520 digital camera. Digital photos were captured using the programmes Deep Focus 3.1 and Quick PHOTO CAMERA 2.3. Layer photos were finally combined with the program Combine ZP.

\section{Tipula (Yamatotipula) stackelbergi Alexander, stat. rev.} http://species-id.net/wiki/Tipula_stackelbergi

Figs 1, 2, 3e, 6a, c, d

Tipula (Tipula) stackelbergi Alexander 1934: 305.

Tipula (Yamatotipula) pruinosa stackelbergi Savchenko 1961: 292. 
Tipula (Yamatotipula) pruinosa stackelbergi Oosterbroek and Theowald 1992: 165. Tipula (Yamatotipula) pruinosa stackelbergi Oosterbroek 2011: http://nlbif.eti.uva.nl/ccw/

Material examined. Holotype of T. stackelbergi: male, pinned specimen (ZISP). "Tigrovaja, Suchan./ rn.Uss.kr. 16.VI/ Stackelberg. 927” (white label, partly hand written, in Cyrillic letters). "81" (white label, handwritten). "HOLOTYPE/ Tipula stackelbergi/ C.P. Alexander" (red label, partly handwritten) (Fig. 1a).

With except of the male hypopygium, the holotype specimen is in rather good condition (Figs 1b, c). All legs are detached from the specimen, but four legs are glued to the pin below the specimen. Tips of wings are broken. Right antenna is broken, only scape and pedicel are left; left antenna has seven flagellomeres. Tip of abdomen is broken; apparently hypopygium is mounted on a celluloid strip, which is attached on a pin. The surface of this strip is heavily cracked, and the structure of the hypopygium cannot be examined.

Other material. Russia, Vladivostok, Nekrutenko leg, 2.VI. 1957, 1 male, 1 female (ZISP).

Redescription. Male. Head yellowish brown, with grey pruinosity. Rostrum yellowish, nasus distinct, bearing numerous light hairs. Palpi brown. Scape yellowish, elongate, length $387-450 \mu \mathrm{m}$, width $126-131 \mu \mathrm{m}(\mathrm{n}=2)$. Pedicel yellowish, globular, length $147 \mu \mathrm{m}$, width $139 \mu \mathrm{m}(\mathrm{n}=1)$. Flagellomere 1 yellowish brown, length $486 \mu \mathrm{m}$, width $91 \mu \mathrm{m}(\mathrm{n}=1)$. Flagellomere 2 length $464 \mu \mathrm{m}$, width $79 \mu \mathrm{m}(\mathrm{n}=1)$. Flagellomeres bear erect short hairs, giving silvery appearance. Flagellomeres 2-7 elongate, brown, with dark verticils (Fig. 1c).

Prescutum with four brown stripes (Fig. 1e). Pronotum, prescutum, scutum, anepisternum, katepisternum and meron brownish, with grey pruinosity. Scutellum, anepimeron and laterotergite yellowish. Anterior part of mediotergite yellowish, more brownish in posterior part, having two weak longitudinal brown stripes. Coxa 1 brown. Anterior part of coxa 2 brown, posterior part yellow. Coxa 3 yellow. Femorae yellowish brown, darkening toward tarsi. Wings without markings, pterostigma brown (Fig. 1f). Wing length $13.8 \mathrm{~mm}(\mathrm{n}=1)$. Halter yellowish.

Abdominal tergites yellowish brown, slightly darkening toward tip of abdomen. $9^{\text {th }}$ tergite with two median projections, densely covered by dark bristles. Lateral corners of $9^{\text {th }}$ tergite glabrous, pointed (Fig. 2a). $9^{\text {th }}$ sternite with median incision, bearing two fleshy and hairy outgrowths in the margin of the incision. Outer gonostylus wormlike, apical half covered by light hairs (Fig. 2b). Inner gonostylus elongate (Figs 2b, c, 3e); beak rounded, with ten stout apical bristles and four subapical weaker bristles; central ridge with few weak bristles along its length; lower beak roundish, not angular. Posterior immovable apodeme of sperm pump almost straight (Fig. 2d). Distal end of compressor apodeme of sperm pump club-shaped, roundish (Fig. 2f). Aedeagal guide as in Fig. 2e.

Female. In general similar to male. Scutellum brown, abdominal tergites brown. Wing length $18.4 \mathrm{~mm}(\mathrm{n}=1)$. Female terminalia as in Fig. 6a. Basal part of hypogynial 


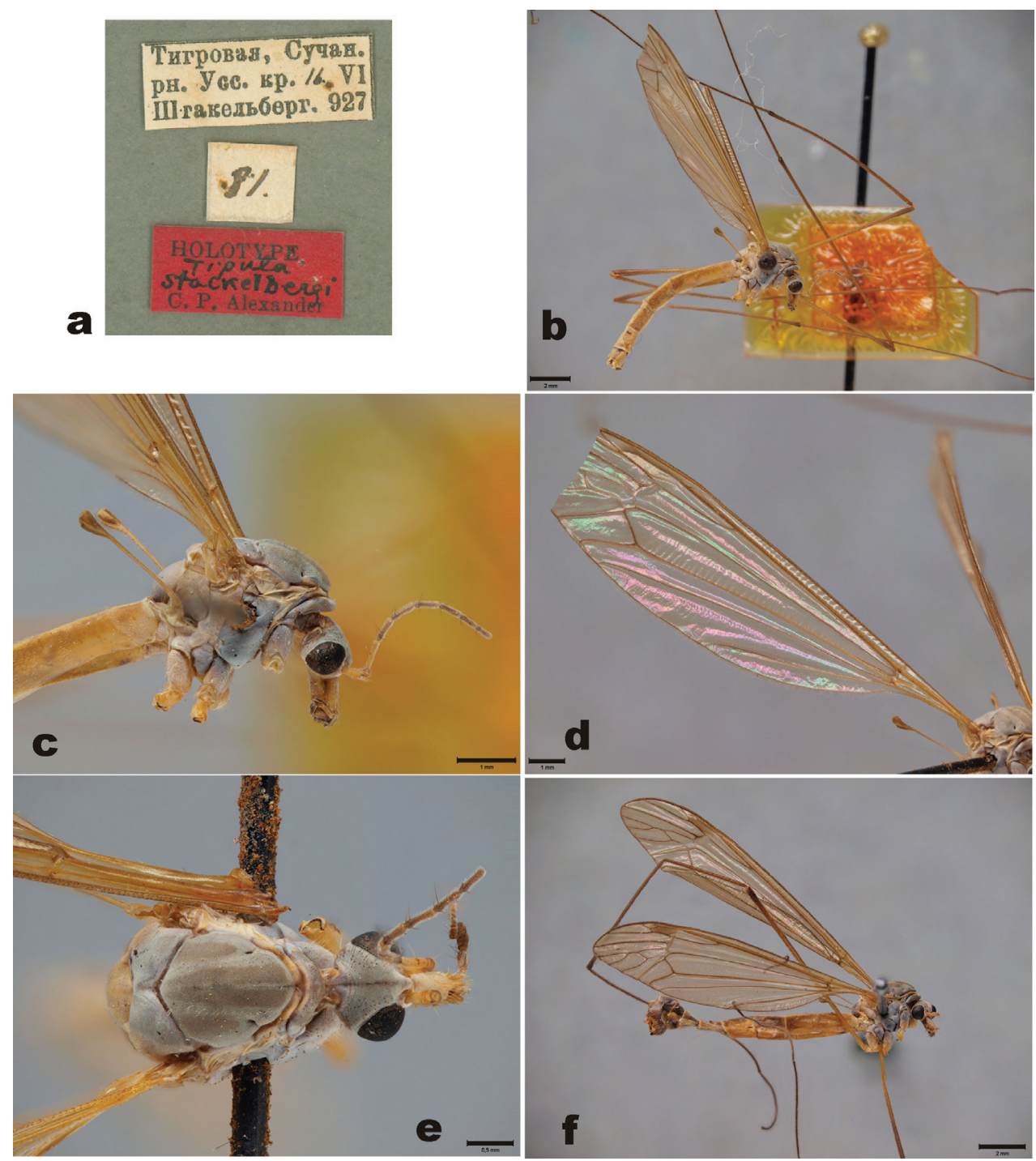

Figure I. Tipula (Yamatotipula) stackelbergi Alexander a Label of the holotype b Holotype male, habitus, lateral view. Yellowish celluloid board is attached below the specimen; most probably C.P. Alexander dissected hypopygium on this board. The surface of the board is heavily cracked, no details of the hypopygium are discernible $\mathbf{c}$ Thorax and head, holotype, lateral view $\mathbf{d}$ Right wing, holotype $\mathbf{e}$ Thorax and head, holotype, dorsal view $\mathbf{f}$ Male (Russia, Vladivostok), habitus, lateral view. Scale bars: b, f 2 mm; c \& d $1 \mathrm{~mm}$; e $0.5 \mathrm{~mm}$.

valves with dense black setae. Proximal ends of valves roundish, tapering toward bases (Fig. 6c). Genital fork of vaginal apodeme brown, rather narrow in its whole length (Fig. 6d). Dorsal view of vaginal apodeme as in Fig. 6d. 


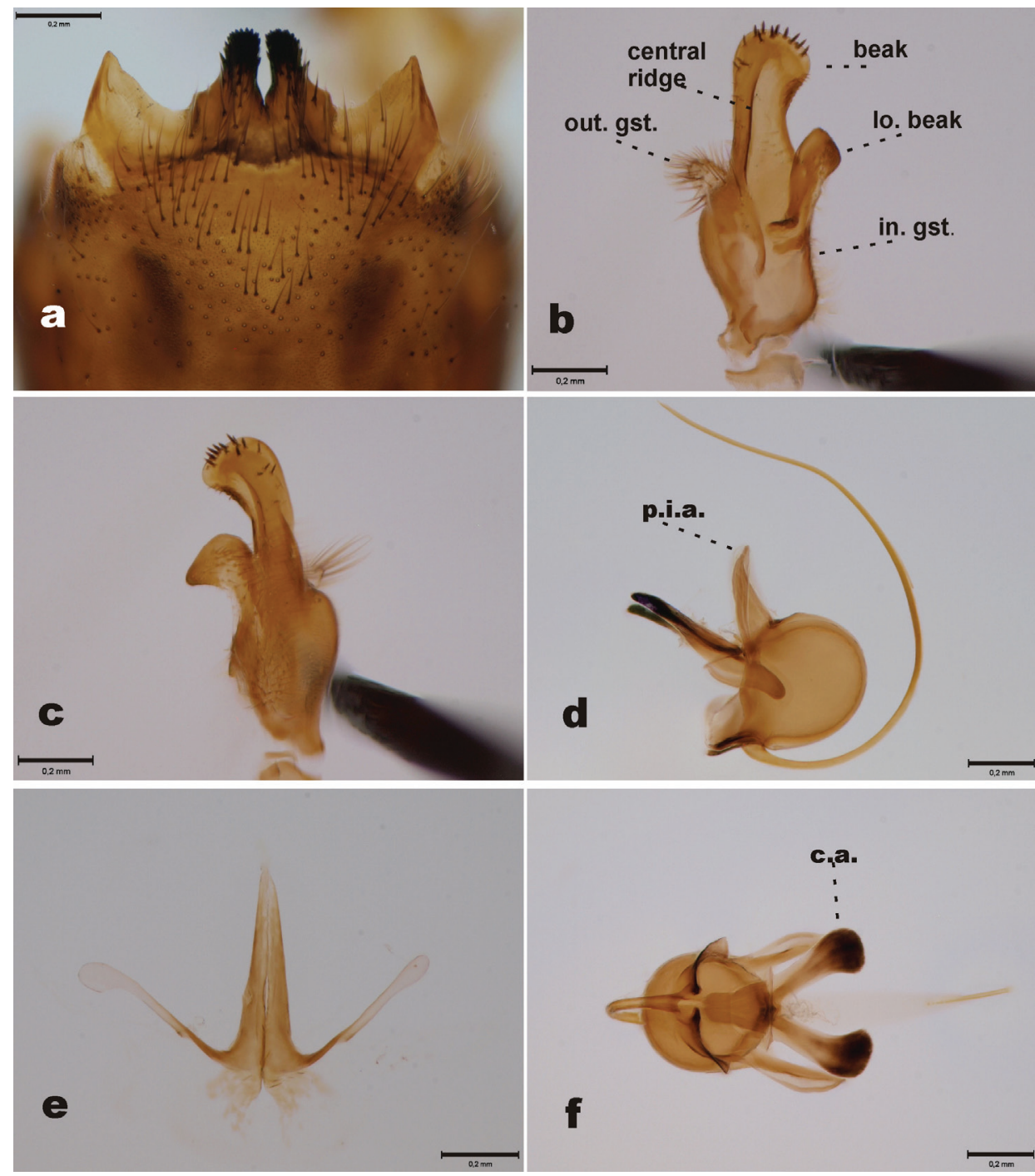

Figure 2. Tipula (Yamatotipula) stackelbergi Alexander, male (Russia, Vladivostok) a $9^{\text {th }}$ tergite, dorsal view $\mathbf{b}$ Outer and inner gonostylus, posterior view; abbreviations: out. gst.= outer gonostylus, in. gst. = inner gonostylus, lo. beak = lower beak c Inner gonostulys, anterior view d Sperm pump, lateral view; abbreviation: p.i.a. = posterior immovable apodeme e Aedeagal guide, dorsal view $\mathbf{f}$ Sperm pump, ventral view; abbreviation: c.a. $=$ compressor apodeme. Scale bars: $0.2 \mathrm{~mm}$.

\section{Tipula (Yamatotipula) pruinosa Wiedemann}

http://species-id.net/wiki/Tipula_pruinosa

Figs 3a-d, 3f-g, 4, 6b, e, f

Tipula pruinosa Wiedemann 1817: 64.

Tipula usuriensis Alexander 1925: 18, syn. n. 
Tipula (Tipula) pruinosa Mannheims 1952: 91.

Tipula (Yamatotipula) pruinosa pruinosa Savchenko 1961: 288.

Tipula (Yamatotipula) pruinosa Oosterbroek and Theowald 1992: 165.

Tipula (Yamatotipula) pruinosa pruinosa Oosterbroek 2011: http://nlbif.eti.uva.nl/ccw/

(for unlisted European references, see Mannheims 1952 and Savchenko 1961).

Material examined. Holotype of T. usuriensis: male, pinned specimen (USNM). "Kudia River/Amagu Siberia/Cockerell/July 1923" (white label, printed). "HOLOTYPE /Tipula/ usuriensis/ C.P. Alexander" (red label, partly handwritten). Slide, permanently mounted wing. "Tipula usuriensis Alex./ $q$ Siberia, Amagu,/ Kudia River/ July 1923, (T.D.A. Cockerell) / The Alexander Collection of Crane-Flies/ HOLOTYPE 2967" (white label, partly handwritten). (Figs 3a, b). The holotype specimen of T. usuriensis is in quite bad condition (Fig. 3c). Half of the abdomen (distal part) and four legs are glued to a card. One wing (length $14.0 \mathrm{~mm}$ ) is slide mounted and one wing is glued to a white card, one leg is also glued to the same card. Scape, pedicel and three flagellomeres of antennae are present. The holotype is also laterally flattened, perhaps due to compression of the freshly collected specimen. Hypopygium was detached by the author from the cardboard, macerated in $\mathrm{KOH}$ and finally preserved in glycerol in a microvial.

Other material. Finland. Savonia borealis: Kiuruvesi, Jynkänjärvi $63.5194^{\circ} \mathrm{N}$; 26.6941 ${ }^{\circ}$ E, 13.VII. 2008, J. Salmela leg, 2 males (ZMUT); Ostrobottnia australis: Ilmajoki, Kivistönmäki $62.8492^{\circ} \mathrm{N} ; 22.6623^{\circ} \mathrm{E}, 1$ female, V.-M. Mukkala leg (PVM); Regio aboensis: Taivassalo, Orikvuori $60.6027^{\circ} \mathrm{N}$; 21.6653 E, 26.VI. 2005 V.-M. Mukkala leg, 1 female (PVM); Regio aboensis: Turku, Piipanoja $60.4918^{\circ} \mathrm{N}$; 22.3017ํㅡ, 22.VI. 2011 A. Teräs leg, 1 female, 4 males (ZMUT).

Redescription of male and female terminalia. Male. $9^{\text {th }}$ tergite (Fig. 4a) essentially similar to $T .(Y$.$) stackelbergi. 9^{\text {th }}$ tergite with two median projections, densely covered by dark bristles, lateral corners of the tergite glabrous, pointed (Fig. 4a). $9^{\text {th }}$ sternite with median incision, bearing two fleshy and hairy outgrowths. Outer gonostylus worm-like, apical half covered by dark hairs (Figs 4b, c). Inner gonostylus elongate. Beak rounded, rather wide, resembling helmet (Figs $4 \mathrm{~b}$, c, $3 \mathrm{f}-\mathrm{g}$ ). Apical portion of beak bearing around 20 stout bristles, central ridge with numerous weak bristles, along the whole length of the ridge. Lower beak angular. Posterior immovable apodeme of sperm pump curved in lateral and ventral view (Figs $4 \mathrm{~d}, \mathrm{f}$ ). Distal end of compressor apodeme of sperm pump truncated (Fig. 4f). Aedeagal guide as in Fig. 4e.

Female. Female terminalia as in Fig. 6b. Basal part of hypogynial valves with dense black setae, proximal ends of valves rounded, widest sub-basally, not tapering toward proximal end (Fig. 6e). Stalk of genital fork gradually widening toward caudal and proximal ends, being narrowest around midpoint (Fig. 6f). Dorsal view of vaginal apodeme as in Fig. $6 \mathrm{f}$.

Geographical variation: The above mentioned description of male terminalia suites well to European specimens. The beak of the inner gonostylus among specimens from Asia is somewhat more i) sinuous, ii) slender and iii) with fewer stout bristles. Variation 

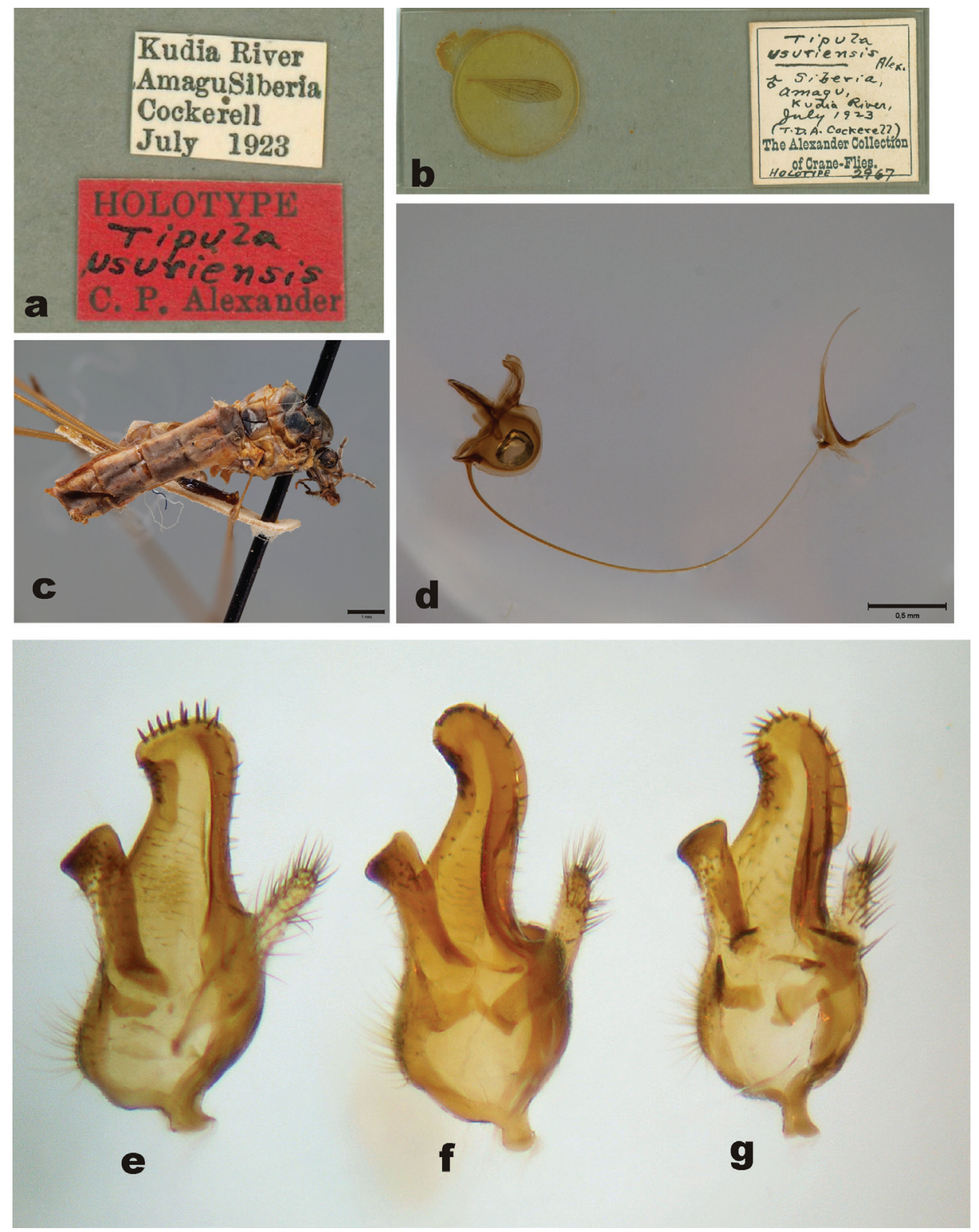

Figure 3. Tipula usuriensis Alexander (=syn. of T. (Yamatotipula) pruinosa Wiedemann), holotype male a Label of the holotype $\mathbf{b}$ Slide mounted wing $\mathbf{c}$ Habitus, lateral view d Sperm pump (lateral view) and aedeagal guide (dorso-lateral view). Scale bars: c $1 \mathrm{~mm}$; d $0.5 \mathrm{~mm}$.

related to the geographical origin of the specimens is not detected in the structure of sperm pump. It is likely that $T$. (Y.) pruinosa sinapruinosa Yang \& Yang, 1993 is similar to the holotype of T. usuriensis and to a male from Russia, Altay. These eastern Palae- 


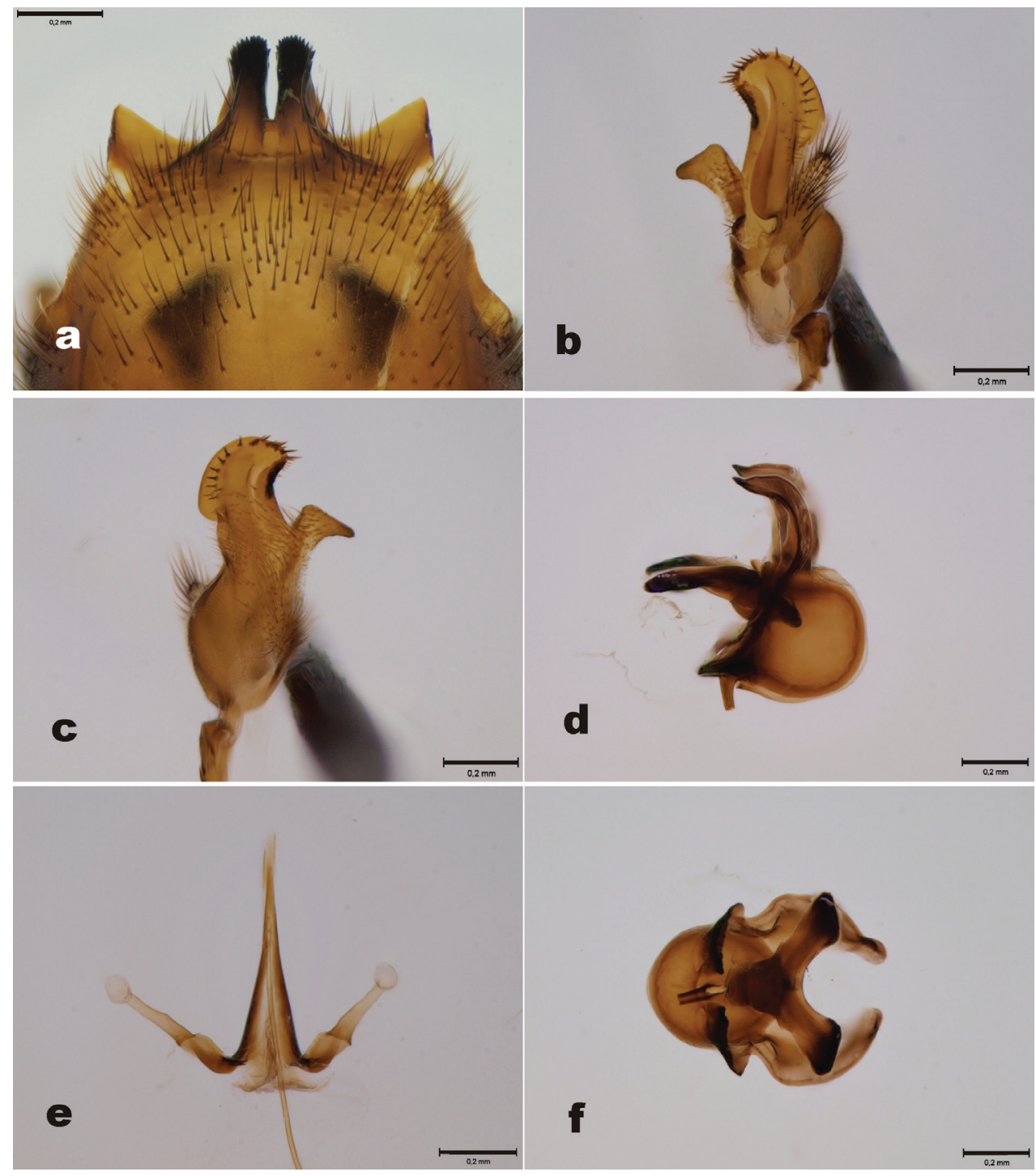

Figure 4. Tipula (Yamatotipula) pruinosa Wiedemann, male (Finland, Turku) a $9^{\text {th }}$ tergite, dorsal view $\mathbf{b}$ Outer and inner gonostylus, posterior view $\mathbf{c}$ Inner gonostulys, anterior view $\mathbf{d}$ Sperm pump, lateral view e Aedeagal guide, dorsal view $\mathbf{f}$ Sperm pump, ventral view. Scale bars $0.2 \mathrm{~mm}$.

arctic specimens could perhaps be given a subspecific or infrasubspecific rank under T. (Y.) pruinosa. However, one widespread species with slight geographic variation in the coloration of head and abdomen (see Alexander 1925; Yang and Yang 1993) and appearance of inner gonostylus is recognized here. 


\section{Tipula (Yamatotipula) freyana Lackschewitz}

http://species-id.net/wiki/Tipula_freyana

Figs $5,7 \mathrm{a}-\mathrm{c}$

Tipula freyana Lackschewitz 1936: 292.

Tipula (Tipula) subpruinosa Mannheims 1954: 42, syn. n.

T. (Yamatotipula) freyana freyana Savchenko 1961: 251.

Tipula (Yamatotipula) freyana Salmela and Autio 2009: 54.

Material examined. Holotype of $T$. subpruinosa: female, pinned specimen (MZHF). "Suomi/ KemL./ Pallastunturit/ 1.8.1951/ leg J. Kaisila" (white label, partly handwritten; backside: "Pyhäkuru" handwritten). "Tipula (Oreom.)/ stigma n. sp./ Mannheims det. 1953" (white label, partly handwritten). "Holotypus" (red label, printed). "Museum/ Helsinki/ Frey" (white label, handwritten). "Mus. Zool. H:fors/ Spec. typ. No 14227/ Tipula/ subpruinosa Mann.” (grayish label, partly handwritten) (Fig. 5a). Pyhäkuru is located in NW Finland, Muonio, PallasYllästunturit National Park, rough coordinates of the type locality are $68.079^{\circ} \mathrm{N}$; $24.083^{\circ} \mathrm{E}$.

The holotype specimen is in good condition (Figs 5b, c, d). Left mid leg is missing, other legs are intact. Right wing has minor rupture proximal to the pterostigma, Costa is slightly damaged. Abdominal terminalia of the specimen were detached by me, macerated in $\mathrm{KOH}$ and later preserved in glycerol in a microvial. This microvial is attached to the same pin as the specimen. The name "stigma" has never been published, and it has most probably been a working title by Mannheims while compiling his first account of Finnish tipulids (Mannheims 1954).

Paratype: female, pinned specimen (ZMUC). "Lpl Sorsele/ Vallnäs $\operatorname{tr} /$ 18.7.1925 / S. Gaunitz" (white-gray label, unclear hand writing) "ex coll./ Peder Nielsen" (white label, printed) "Tipula (Tipula) / subpruinosa n sp.) / Mannheims det 1953" (white label, partly handwritten) "Tipula (Tipula) / subpruinosa n sp.) / Mannheims det 1953" (white label, partly handwritten) "Paratypoid" (red label, printed). The paratype specimen is in rather bad condition. Left antenna has nine and right antenna ten segments. All legs are broken, remnants of two legs are glued to a card below the specimen.

Other material. Finland. Karelia borealis: Lieksa, Nurmespuro $63.4030^{\circ} \mathrm{N}$; 28.1972 ${ }^{\circ}$ E, 19.VI.-14.VII. 2008, J. Salmela leg, 2 females (ZMUT); Lapponia kemensis pars occidentalis: Kittilä, Palovaara E $68.0054^{\circ} \mathrm{N} ; 24.7736^{\circ} \mathrm{E}, 23 . \mathrm{VI}$. $2009 \mathrm{~J}$. Salmela leg, 1 female (ZMUT); Lapponia enontekiensis: Enontekiö, Tarvantovaara, Pahtavaara SE $68.6518^{\circ} \mathrm{N} ; 22.5909^{\circ} \mathrm{E}, 11$. VI.-19.VII. 2009, J. Salmela leg, 2 males, 1 female.

Description of female terminalia. Female terminalia as in Fig. 7a. Basal part of hypogynial valves with modest setosity, proximal ends of valves pointed (Fig. 7b). Genital fork of vaginal apodeme dark brown, slightly sinuous in lateral view. Dorsal view of vaginal apodeme and genital fork as in Fig. 7c. 

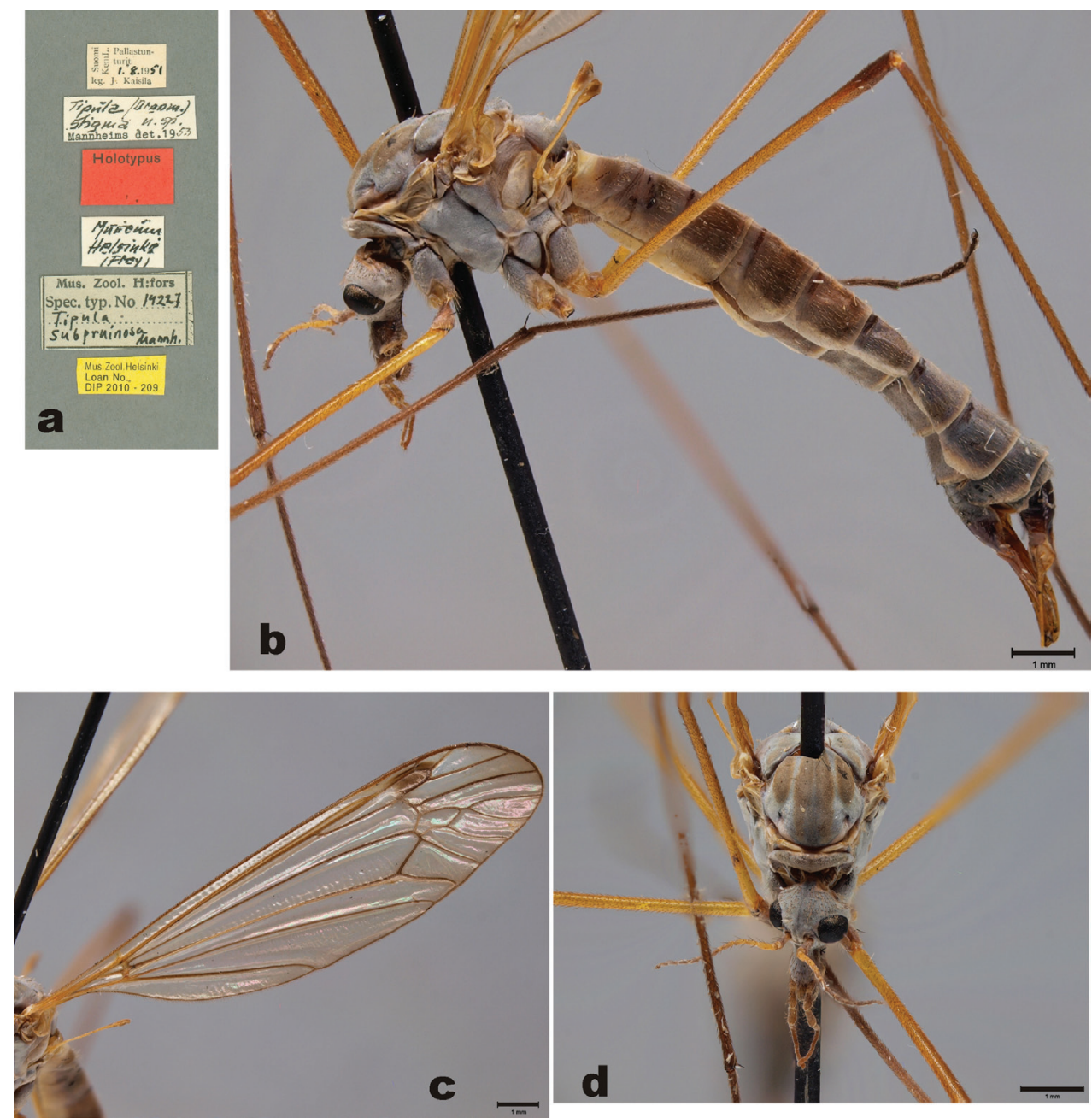

Figure 5. Tipula subpruinosa Mannheims (=syn. of T. (Yamatotipula) freyana Lackschewitz), holotype female a Label $\mathbf{b}$ Habitus, lateral view $\mathbf{c}$ Left wing d Thorax and head, dorsal view. Scale bars: $1 \mathrm{~mm}$.

\section{Key to the Tipula (Y.) pruinosa and T. (Y.) stackelbergi}

$1 \quad$ Males 2

Females..................................................................................... 3

2 Beak of inner gonostylus relatively wide, helmet-like, with numerous (ca. 20) stout bristles (Figs 4b, c). Sperm pump dark, posterior immovable apodeme curved in lateral and ventral view (Figs $4 \mathrm{~d}, \mathrm{f}$ ) ....................T. (Y.) pruinosa

- $\quad$ Beak of inner gonostylus rather narrow, with ca. 10 stout bristles (Figs 2 b, c). Sperm pump lighter, posterior immovable apodeme almost straight in lateral and ventral view (Figs 2d, f) 

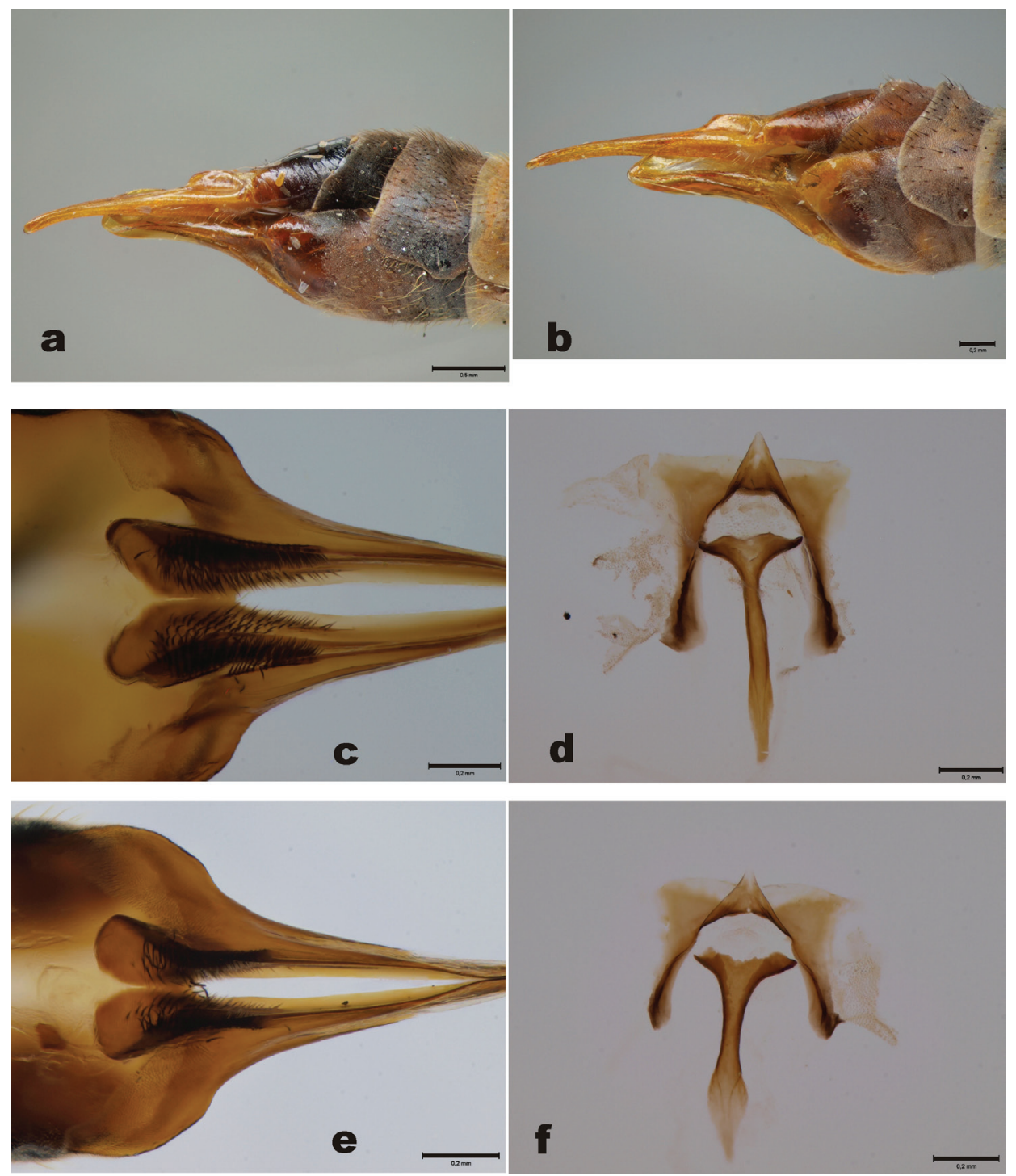

Figure 6. Female terminalia. Tipula (Yamatotipula) stackelbergi Alexander (Russia, Vladivostok) a Female cerci, lateral view, pinned specimen $\mathbf{c}$ Hypogynial valves, dorsal view $\mathbf{d}$ Vaginal apodeme and genital fork, dorsal view. Tipula $(Y$.) pruinosa Wiedemann (Finland, Turku) b female cerci, lateral view, pinned specimen e Hypogynial valves, dorsal view $\mathbf{f}$ Vaginal apodeme and genital fork, dorsal view. Scale bars: a 0.5 $\mathrm{mm}$; b, c, d, e, f $0.2 \mathrm{~mm}$.

3 Basal part of hypogynial valves widest sub-basally, not tapering toward base (Fig. 6f). Stalk of genital fork gradually widening toward caudal and proximal ends, being narrowest around midpoint (Fig. 6g) ................T. (Y.) pruinosa

- Basal part of hypogynial valves roundish, tapering toward base (Fig. 6d). Genital fork rather narrow in its whole length (Fig. 6e) .. T. (Y.) stackelbergi 

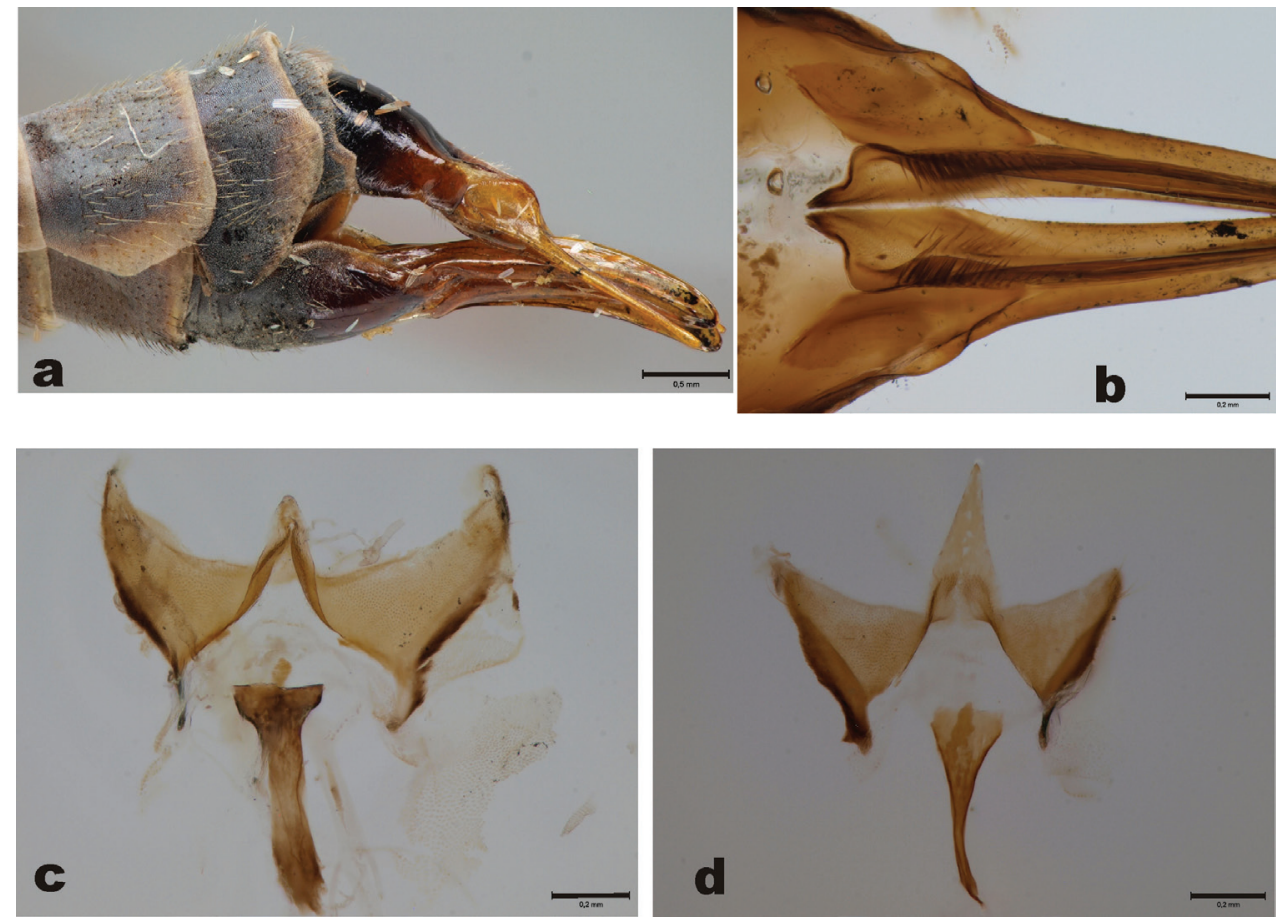

Figure 7. Female terminalia. Tipula $(Y$.$) freyana Lackschewitz (holotype of T. subpruinosa Mannheims$ (Finland, Pallastunturit) a Female cerci, lateral view, pinned specimen b Hypogynial valves, dorsal view c Vaginal apodeme and genital fork, dorsal view. Tipula (Y.) chonsaniana Alexander (Finland, Taivalkoski) d Vaginal apodeme and genital fork, dorsal view.

\section{Key to the females of Tipula (Yamatotipula) moesta and related species}

1 Body coloration dark; scape, pedicel and $1^{\text {st }}$ flagellomere dark brown T. (Y.) moesta

- $\quad$ Body coloration lighter; scape, pedicel and $1^{\text {st }}$ flagellomere yellowish .2 Stalk (proximal 2/3) of genital fork very narrow, needle-like (Fig. 7d) T. (Y.) chonsaniana - $\quad$ Stalk (proximal 2/3) of genital fork wider, as in Fig. 7c T. (Y.) freyana

\section{Discussion}

In the present paper I suggest three changes to the nomenclature of Palaearctic Tipulidae: i) Tipula (Yamatotipula) stackelbergi is a valid species, not a subspecies of $T$. (Y.) pruinosa ii) Tipula usuriensis is neither a valid species nor a synonym of $T$. $(Y$.) stackelbergi, it is instead a junior synonym of $T$. (Y.) pruinosa and iii) Tipula subpruinosa is not a synonym of $T$. (Y.) stackelbergi, it is a junior synonym of $T$. ( $Y$.) freyana. It 
remains questionable whether $T .(Y$.$) pruinosa sinapruinosa is a valid subspecies. Based$ on the original description (Yang and Yang 1993) it is likely that Chinese specimens are conspecific with other eastern Palaearctic $T .(Y$.$) pruinosa specimens. If these eastern$ Palaearctic specimens are to be ranked as subspecies below $T$. (Y.) pruinosa, T. usuriensis is the oldest available name for the taxon. However, as discussed above, subspecies should be delineated through several criteria, e.g. ecology and genetics. More data on Asian $T$. (Y.) pruinosa populations should be available for the assessment of speciation and reliable use of subspecific rank.

Tipula (Y.) pruinosa and T. (Y.) stackelbergi are closely related but valid species. The species pair is well separated due to the differences in male genitalia (see the key to the species), but less so regarding female genitalia. More females of $T$. (Y.) stackelbergi should be studied in order to firmly validate the diagnostic differences presented here. Tipula ( $Y$.) stackelbergi is a very rarely collected species, known only from East Siberia and the Russian Far East (Alexander 1934; Savchenko 1961; Pilipenko 2009).

Tipula subpruinosa, described from Finland and Sweden, was thought to be a synonym of T. (Y.) stackelbergi (Savchenko 1961; Oosterbroek and Theowald 1992). Due to this tentative synonymy, $T$. $(Y$.) stackelbergi was erroneously thought to be present in Fennoscandia. However, examination of the holotype of T. subpruinosa revealed that the species is a junior synonym of $T$. ( $Y$. .) freyana, not $T$. (Y.) stackelbergi. Hence, T. (Y.) stackelbergi should be removed from the list of European crane flies. It should be noted that the description of T. subpruinosa was very short and lacking any figures; it is not surprising it led to fallacious interpretation. In a similar vein, T. usuriensis was also tentatively synononymized by Savchenko (1961) with T. (Y.) stackelbergi. In his description of T. usuriensis Alexander (1925) provided figures depicting male $9^{\text {th }}$ tergite and lateral view of hypopygium, but these figures can now be considered too general to discriminate between $T$. (Y.) pruinosa and $T$. (Y.) stackelbergi.

Compared to Tipula $(Y$.$) stackelbergi and T$. (Y.) pruinosa, $T$. (Y.) freyana is phylogenetically rather distant to these two species, being instead close to $T$. ( $Y$.) moesta Riedel and T. (Y.) chonsaniana Alexander (e.g. Salmela and Autio 2009). Although illustrations of male hypopygium, or parts of it, of $T$. (Y.) freyana have been provided by several authors (see Salmela and Autio 2009), no figures of female terminalia have been hitherto published. A key to the females of $T$. (Y.) chonsaniana, $T$. (Y.) freyana and $T$. $(Y$.$) moesta explains the diagnostic differences between these three species (see above).$ Figures of female genital forks of $T$. (Y.) moesta and $T$. (Y.) chonsaniana were provided by Salmela and Autio (2009).

\section{Acknowledgements}

I am indebted to the following persons for information and/or the loan of specimens: Nikolai Paramonov (St. Petersburg), Pekka Vilkamaa (Helsinki), Jon Gelhaus (Philadelphia), David G. Furth, Patricia Gentili-Poole (Washington), Thomas Pape (Copenhagen), Valentin Pilipenko (Moscow) and Veli-Matti Mukkala (Kaarina). Julia 
Kuosmanen and Liisa Puhakka (Turku) are thanked for translations of Russian texts. Constructive comments by Fenja Brodo (Ottawa) and John Kramer (Leicester) improved the manuscript.

\section{Refenrences}

Alexander CP (1925) Crane flies from the Maritime Province of Siberia. Proceedings of the United States National Museum 68(4): 1-21. doi: 10.5479/si.00963801.68-2605.1

Alexander CP (1934) New or little-known Tipulidae from eastern Asia (Diptera). XVI. Philippine Journal of Science 52: 305-348.

Alexander CP, Byers GW (1981) Tipulidae 7. In: McAlpine JF, Peterson BV, Shewell GE, Teskey HJ, Vockeroth JR, Wood DM (Eds) Manual of Nearctic Diptera 1. Monograph No. 27, Biosystematic Research Institute, Ottawa, Ontario, 153-190. http://www.esc-sec. ca/aafcmonographs/manual_of_nearctic_diptera_vol_1.pdf

Ball RM, Avise JC (1992) Mitochondrial DNA phylogeographic differentiation among avian populations and the evolutionary significance of subspecies. The AUK 109: 626-636.

Frommer SI (1963) Gross morphological studies of the reproductive system in representative North American crane flies (Diptera: Tipulidae). Kansas University Science Bulletin 44: $535-625$.

Haig SM, Beever EA, Chambers SM, Draheim HM, Dugger BD, Dunham S, Elliot-Smith E, Fontaine JB, Kesler DC, Knaus BJ, Lopes IF, Loschl P, Mullins TD, Sheffield LM (2006) Taxonomic considerations in listing subspecies under the U.S. Endangered Species Act. Conservation Biology 20: 1584-1594. doi: 10.1111/j.1523-1739.2006.00530.x

Hewitt GM (2002) Hybrid zones. Encyclopedia of Life Sciences, 1-8. doi: 10.1038/npg. els. 0001752

Kothera L, Zimmerman EM, Richards CM, Savage HM (2009) Microsatellite characterization of subspecies and their hybrids in Culex pipiens complex (Diptera: Culicidae) mosquitoes along a north-south transect in the Central United States. Journal of Medical Entomology, 46: 236-248. doi: 10.1603/033.046.0208

Lackschewitz P (1936) Das Genus Tipula (Diptera Nematocera) in der Arktis und dem borealen Waldgebiet Eurasiens. Travaux de l'Institut Zoologique de l'Academie des Sciences de l'USSR 4: 245-312.

Mannheims B (1952) 15. Tipulidae. In: Lindner E (Ed) Die Fliegen der palaearktischen Region, 3(5)1, Lief. 170: 65-112.

Mannheims B (1954) Die Tipuliden Ostfennoskandiens (Dipt.). Notulae Entomologicae 34: $29-50$.

Miller JM, Hallager S, Monfort SL, Newby J, Bishop K, Tidmus SA, Black P, Houston B, Matthee CA, Fleischer RC (2011) Phylogeographic analysis of nuclear and mtDNA supports subspecies designations in the ostrich (Struthio camelus). Conservation Genetics 12:423431. doi: 10.1007/s10592-010-0149-x

O'Brien SJ, Mayr E (1991) Bureaucratic mischief: recognizing endangered species and subspecies. Science 251: 1187-1188. doi: 10.1126/science.251.4998.1187 
Oosterbroek P (1980) The western palaearctic species of Nephrotoma Meigen, 1803 (Diptera, Tipulidae), part 5, Phylogeny and Biogeography. Beaufortia 29: 311-393.

Oosterbroek P (2011) Catalogue of the Craneflies of the World (Diptera, Tipuloidea: Pediciidae, Limoniidae, Cylindrotomidae, Tipulidae) http://nlbif.eti.uva.nl/ccw/index.php

Oosterbroek P, Theowald B (1992) Family Tipulidae. In: Soós Á, Papp L, Oosterbroek P (eds) Catalogue of Palaearctic Diptera 1. Hungarian Natural History Museum, Budapest, 56-178.

Oosterbroek P, Dufour C, Pilipenko V (2001) On the presence of Dolichopeza (subgenus Oropeza) in the westpalaearctic (Diptera, Tipulidae). Bulletin de la Societe Neuchateloise des Sciences Naturelles 124: 119-123.

Patten MA, Unitt P (2002) Diagnosability versus mean differences of Sage sparrow subspecies. The Auk 119: 26-35. doi: 10.1642/0004-8038(2002)119[0026:DVMDOS]2.0.CO;2

Phillimore AB, Owens IPF (2006) Are subspecies useful in evolutionary and conservation biology? Proceedings of the Royal Society. B 273: 1049-1053. doi: 10.1098/rspb.2005.3425

Phillimore AB, Orme CDL, Davies RG, Hadfield JD, Reed WJ, Gaston KJ, Freckleton RP, Owens IPF (2007) Biogeographical basis of recent phenotypic divergence among birds: a global study of subspecies richness. Evolution 61: 924-957. doi: 10.1111/j.15585646.2007.00068.x

Pilipenko VE (2009) Tipulidae. In: Insects of Lazovsky Nature Reserve. Russian Academy of Science Far Eastern Branch, Institute of Biology and Soil Science, Dalnauka, Vladivostok: 328-331. [in Russian]

Salmela J, Autio O (2009) Tipula (Yamatotipula) moesta Riedel and related species in Finland (Diptera, Tipulidae). Entomologica Fennica 20: 49-55.

Savchenko EN (1961) Crane-flies (Diptera, Tipulidae), Subfam. Tipulinae, Genus Tipula L., (part 1). Fauna USSR, N.S. 79, Nasekomye Dvukrylye (Diptera) 2(3): 1-487. [in Russian]

Starý J (2006) Nomenclatural changes in West Palaearctic Limoniidae and Pediciidae (Diptera). Acta Universitatis Carolinae, Biologica 49: 175-186.

Starý J, Brodo F (2009) Arctic species of the subgenus Symplecta sensu stricto (Diptera: Limoniidae). Canadian Entomologist 141: 1-30. doi: 10.4039/n08-031

Tsao W-C, Yeh W-B (2008) DNA-based discrimination of subspecies of swallowtail butterflies (Lepidoptera: Papilioninae) from Taiwan. Zoological Studies 47: 633-643. http://zoolstud.sinica.edu.tw/Journals/47.5/633.pdf

Wiedemann CRW (1817) Neue Zweiflugler (Diptera) aus der Gegend um Kiel. Zoologisches Magazin, Kiel 1: 61-86.

Wilson EO, Brown WL (1953) The subspecies concept and its taxonomic application. Systematic Zoology 2: 97-111. doi: 10.2307/2411818

Yang D, Yang C (1993) Two new species and a new subspecies of Tipula from China (Diptera: Tipulidae). Acta Agriculturae Universitatis Pekinensis 19: 97-100. [in Chinese with English summary] 